\title{
RESENHA DE LIVRo Desencontro do médico com o paciente: o que pensam os médicos?
}

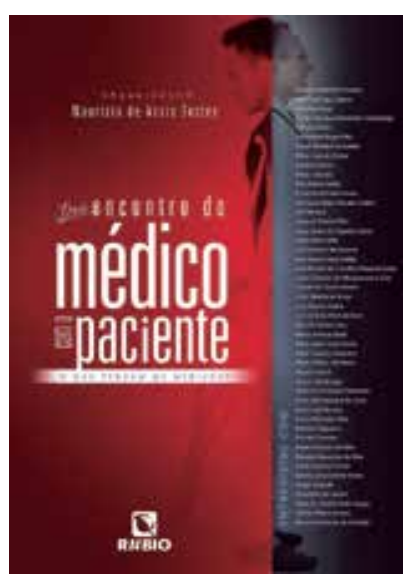

\section{Doctor's mismatch with the patient: what do you think doctors?}

José Carlos Souza', Ceny Longhi Rezende², Anderson Borges de Carvalho ${ }^{3}$, Heloísa Bruna Grubits ${ }^{4}$

O livro "Desencontro do médico com o paciente: o que pensam os médicos?"1 foi organizado com maestria pelo eminente psiquiatra Dr. Maurício de Assis Tostes, que é professor da disciplina de Psicologia Médica da Faculdade de Medicina da Universidade Federal do Rio de Janeiro (UFRJ). Ele vem contribuir com a formação dos futuros médicos, assim como com a educação continuada dos já existentes.

Em um momento crítico de discussões políticas e técnico-pedagógicas sobre a abertura de novas escolas médicas, assim como da proliferação das instituições privadas de ensino, é muito oportuno que se discuta qual o perfil do profissional de Medicina se pretende formar. Por conta disso, o Ministério da Educação e o Conselho Nacional de Educação, por meio da Resolução no 3, de 20 de junho de 2014, instituíram as novas Diretrizes Curriculares Nacionais do Curso de Graduação em Medicina, estabelecendo três metas primordiais para a formação médica: Atenção em Saúde, Gestão em Saúde e Educação em Saúde. Esses três pilares têm como objetivo principal a formação de um médico crítico, ético, reflexivo e humano. Para esse fim, a partir do ano de 2019 todos os cursos de Medicina contarão em seus currículos com as metodologias ativas de aprendizagem, em que o ensino é centrado no estudante, e não no professor, visando, entre tantos objetivos, ao maior comprometimento do discente na sua formação.

O Prof. Dr. Maurício e os seus 47 entrevistados vêm antecipar muito do que se pretende com os novos médicos, pois alguns aspectos são coincidentes nas diversas entrevistas realizadas pelo autor. O médico deve aprender a cuidar do outro como de si mesmo, o que se chama de empatia e alteridade. Isso tudo em uma prática médica dialógica e não hegemônica, haja vista que os pacientes já possuem controle social do processo saúde-doença bem maior que nos vetustos tempos.

É conveniente que, numa resenha feita para uma revista de Psiquiatria, seja mencionado que houve ênfase especial nas entrevistas feitas com os psiquiatras e/ou psicanalistas, como Eustachio Portella Nunes, Marco Antônio Brasil, Mário Alfredo De Marco, Cláudio Eizirik, Neury Botega, Luiz Alberto Hetem, Renério Fráguas, Marcelo Santos Cruz, Maria Tavares Cavalcanti, Sandra Fortes e Sérgio Zaidhaft.

Dentre alguns entrevistados, destacam-se colegas de muitas das principais especialidades e de diversas universidades brasileiras, alguns deles membros da Academia Nacional de Medicina, como Eustachio Portella Nunes [professor titular de Psiquiatria do Instituto de Psiquiatria, diretor do Instituto de Psquiatria (IPUB); atualmente professor emérito da Universidade Federal do Rio de Janeiro (UFRJ)], Adib Jatene, Paulo Niemeyer Filho, Ivo Pitanguy, Clementino Fraga Filho e Alice Rosa (estes dois últimos expoentes na área de educação médica na UFRJ).

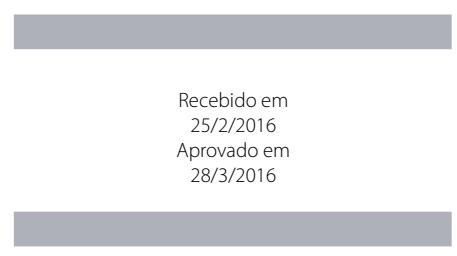

DOI: $10.1590 / 0047-2085000000124$
1 Universidade Estadual de Campinas (Unicamp); Universidade de Lisboa, Portugal; Universidade Estadual de Mato Grosso do Sul (UEMS). 2 Universidade Católica Dom Bosco (UCDB); Empresa Ebserh - Universidade Federal da Grande Dourados (UFGD), Hospital Universitário, Centro Obstétrico.

3 UCDB; Hospital de Câncer de Campo Grande.

4 Unicamp; UCDB.

Endereço para correspondência: José Carlos Souza

Rua Theotonio Rosa Pires, 88, Vila Rosa Pires

Telefone: (67) 9981-6271

79004-340 - Campo Grande, MS, Brasil

E-mail: josecarlossouza@uol.com.br 
Por fim, é primordial refletir que a psiquiatria passa por intensas transformações nos últimos anos, seja no campo do diagnóstico ou do tratamento, com impacto na relação psiquiatra-paciente, daí a premência desse tema, que infelizmente não recebe ainda a devida atenção.

\section{REFERÊNCIA}

1. Tostes MA (Org.). Desencontro do médico com o paciente: 0 que pensam os médicos? Rio de Janeiro: Rubio; 2014 